\title{
Percutaneous Electrical Nerve Stimulation (PENS) as a Rehabilitation Approach for Reducing Mixed Chronic Pain in Patients with Musculoskeletal Disorders
}

\author{
Alessandro de Sire ${ }^{1, *(\mathbb{D})}$, Antonio Ammendolia ${ }^{1} \mathbb{D}$, Lorenzo Lippi ${ }^{2} \mathbb{D}$, Giacomo Farì $^{3}\left(\mathbb{D}\right.$, Carlo Cisari $^{2}$ and $^{-}$ \\ Marco Invernizzi $2,4, *$ (D) \\ 1 Department of Medical and Surgical Sciences, University of Catanzaro "Magna Graecia”, \\ 88100 Catanzaro, Italy; ammendolia@unicz.it \\ 2 Physical and Rehabilitative Medicine, Department of Health Sciences, University of Eastern Piedmont, \\ 28100 Novara, Italy; lorenzolippi.mt@gmail.com (L.L.); cisari50@gmail.com (C.C.) \\ 3 Motor and Sports Sciences, Department of Sciences and Biological and Environmental Technologies, \\ Salento University, 73100 Lecce, Italy; dr.giacomofari@gmail.com \\ 4 Translational Medicine, Dipartimento Attività Integrate Ricerca e Innovazione (DAIRI), Azienda Ospedaliera \\ SS. Antonio e Biagio e Cesare Arrigo, 15121 Alessandria, Italy \\ * Correspondence: alessandro.desire@unicz.it (A.d.S.); marco.invernizzi@med.uniupo.it (M.I.); \\ Tel.: +39-096-171-2819 (A.d.S.); +39-032-137-34800 (M.I.)
}

check for updates

Citation: de Sire, A.; Ammendolia, A.; Lippi, L.; Farì, G.; Cisari, C.; Invernizzi, M. Percutaneous Electrical Nerve Stimulation (PENS) as a Rehabilitation Approach for Reducing Mixed Chronic Pain in Patients with Musculoskeletal Disorders. Appl. Sci. 2021, 11, 4257. https://doi.org/10.3390/app11094257

Academic Editor: Francesca Silvagno

Received: 14 April 2021

Accepted: 4 May 2021

Published: 8 May 2021

Publisher's Note: MDPI stays neutral with regard to jurisdictional claims in published maps and institutional affiliations.

Copyright: (c) 2021 by the authors. Licensee MDPI, Basel, Switzerland. This article is an open access article distributed under the terms and conditions of the Creative Commons Attribution (CC BY) license (https:/ / creativecommons.org/licenses/by/ $4.0 /)$.
Abstract: "Mixed pain" is a term recently introduced to define the overlapping of nociceptive, neuropathic and nociplastic pain. To date, it has been reported that pharmacological treatments might have a modest effectiveness on patients affected by mixed chronic pain, with detrimental consequences in terms of disability, physical function and health-related quality of life. In this scenario, Percutaneous Electrical Nerve Stimulation (PENS), a mini-invasive neuromodulation technique, has been recently suggested as a promising approach for the complex management of mixed pain in musculoskeletal disorders. Albeit PENS showed to be effective in reducing unspecified pain in several chronic pain conditions, there is still a lack of evidence in the literature about its role in the management of neuropathic or mixed pain not responsive to pharmacological treatments. Therefore, by the present scoping review, we portray the potential effects of PENS in the multidisciplinary and multidimensional management of mixed chronic pain in patients with musculoskeletal disorders.

Keywords: percutaneous electric nerve stimulation; chronic pain; rehabilitation; neuromodulation; disability

\section{Introduction}

Pain is "an unpleasant sensory and emotional experience associated with, or resembling that associated with, actual or potential tissue damage" [1]. Pain classification has been recently revised in order to overcome the challenging and over-simplistic categorization in purely neuropathic or purely nociceptive pain [1]. In this scenario, the term "mixed pain" has been recently introduced in order to characterize the overlapping of nociceptive, neuropathic and nociplastic pain [2]. This complex clinical presentation could be phenotypically heterogeneous and characterized by a simultaneous presentation of nociceptive, neuropathic and nociplastic pain [2].

The term "mixed pain" has been recently proposed to describe a condition characterized by the concomitant presence of specific symptoms referrable to both nociceptive and neuropathic pain [3]. Although mixed pain has not been mentioned in the recent IASP classification, the current literature on this topic is exponentially raising exploring its occurrence in several pathological conditions such as low back pain (LBP), osteoarthritis, postsurgical and cancer pain. Moreover, mixed pain in these chronic pathological conditions contributes to increased disability and impairment in terms of both physical function and health-related quality of life (HRQoL) [3]. 
In this context, the Percutaneous Electrical Nerve Stimulation (PENS) is a miniinvasive neuromodulation technique that has been recently suggested as a promising therapeutic intervention for the management of mixed and refractory pain in different clinical conditions [4]. Moreover, this novel technique might be used to reduce both pain perception in several musculoskeletal diseases of Physical Medicine and Rehabilitation (PRM) interest, including LBP [5], total knee arthroplasty [6], chronic pain after amputation [7], opioid-resistant cancer pain [8] and overactive bladder in children [9]. Although PENS showed to be effective in reducing unspecified pain in several chronic pain conditions, there is still a lack of evidence in the literature about its role in the management of neuropathic or mixed pain in musculoskeletal disorders not responsive to pharmacological treatments.

Therefore, this scoping review aimed at summarizing the current literature focusing on the mechanisms of action, clinical indications, safety and effectiveness of PENS treatment in patients affected by mixed chronic pain conditions in the rehabilitation field.

\section{Musculoskeletal Disorders Characterized by Mixed Chronic Pain}

Pain is commonly classified in three different entities with peculiar characteristics: nociceptive, neuropathic and nociplastic [10]. More in detail, nociceptive pain could be defined as a protective system from potentially dangerous stimuli acting on nociceptors after tissue damage and transducing the signal through unmyelinated $\mathrm{C}$ fibers and thinly myelinated $\mathrm{A} \delta$ fibers [11]. Conversely, neuropathic pain is generated by a lesion or disease of the somatosensory nervous system and is considered a maladaptive pain consequent to a diseased state of the nervous system [12]. Lastly, nociplastic pain arises from an altered nociception despite no clear evidence of actual or threatened tissue damage, and without any evidence of a somatosensory system lesion [1].

Most patients suffering from neuropathic pain require pharmacological treatment, including first-line drugs, calcium-channel-acting modulators (pregabalin, gabapentin), tricyclic antidepressants and serotonin-noradrenalin reuptake inhibitors (duloxetine, venlafaxine). Moreover, second-line pharmacological approaches include several interventions such as lidocaine patches, capsaicin, tramadol and opioids (morphine and oxycodone) and botulinum toxin-A [13,14].

Pain could be also classified as acute, sub-acute and chronic [10]. Chronic pain is defined as a painful condition lasting more than 3 months and is a crucial issue in several pathological conditions with detrimental effects on Health-Related Quality of Life (HRQoL), disability and, as a consequence, on direct and indirect sanitary costs [15].

Although, at present, several therapeutic options are available for the management of chronic pain, a consistent number of patients might experience a persistent or refractory pain [16-18]. In particular, more than one-half of patients suffering from neuropathic pain are refractory to a single agent, suggesting that a combined therapy with different pharmacological agents such as antiepileptic and antidepressant drugs might be more effective to treat this condition in these patients [2]. However, a multidisciplinary approach is strongly recommended in patients not achieving relevant benefits from single interventions, including psychoeducational interventions, mind-body therapies and physical exercise [19]. Unfortunately, evidence about the effectiveness of specific drug combinations in patients suffering mixed chronic pain is still lacking, and the safety of combined pharmacological treatments has still not been fully assessed [20].

In this context, a main component of mixed chronic pain is neuropathic pain, defined as a consequence of various nerve damaging stimuli, which could affect both the peripheral and the central nervous system, thus representing a somatosensory system dysfunction or damage [12,21]. However, the maladaptive process sustaining the persistence of neuropathic pain is only a central mechanism, also involving satellite glia and autonomic neurons, which take part in a pain-promoting state in response to axonal damage [22].

A recent systematic review [23] highlighted that neuropathic pain components might be experienced in 20 to $55 \%$ of LBP patients. Moreover, the majority of these patients seem 
to experience symptoms referrable to both neuropathic and nociceptive components [2]. Similarly, the recent systematic review and meta-analysis by French et al. [24] reported that patients with osteoarthritis might experience pain with neuropathic features in $23 \%$ of cases, suggesting that knee osteoarthritis is characterized by both nociceptive and neuropathic pain components.

Pharmacological therapy (e.g., gabapentin, pregabalin, serotonin/noradrenaline reuptake inhibitors and tricyclic antidepressants) has been considered the first-line approach for patients with mixed pain for several years, albeit a recent meta-analysis showed that these pharmacological treatments had a modest effectiveness in this condition [25]. In light of these considerations, mixed chronic pain is a multifactorial and complex pathological entity that often requires multidisciplinary management, including different professional figures such as PRM physicians, algologists, psychiatrists and physical therapists [5,25]. In this context, several non-pharmacological rehabilitative approaches have been proposed to treat all the features of chronic pain, including physical exercise therapy, psychoeducational interventions, physical therapies (e.g., transcutaneous electrical nerve stimulation (TENS)) and novel interventional techniques (e.g., oxygen-ozone therapy) [13,26,27].

In this complex scenario, PENS has been proposed as a promising neuromodulation approach for the management of mixed chronic pain in patients affected by musculoskeletal disorders [4].

\section{Percutaneous Electrical Nerve Stimulation (PENS)}

PENS is a mini-invasive neuromodulation technique that alters nerve impulses at the subcutaneous level and might be effective in chronic and refractory pain management [28]. Moreover, the mechanisms underpinning its positive effects in neuropathic pain management involve the physiological gate control theory, recently implemented and revisited [29].

To date, the gate control regulation theory indicates that inhibitory interneurons at the spinal level are the keys that might open or close "the gate" to the painful sensation [30]. However, a large heterogeneity of interneurons has been identified, both excitatory (pain facilitation) and inhibitory (pain inhibition). It has been hypothesized that specific anterograde signals might play a crucial role in gate control regulation; however, despite the progress in the last decades in pain modulation circuits understanding, the precise mechanisms underpinning inhibitory interneurons spinal circuits are far from being fully understood [29].

In this scenario, a growing interest has been rising in the research field about neuronmicroglia communication with intriguing implications in neuropathic pain modulation. Tsuda et al. [31] recently suggested that the purinergic receptor P2 $\times 4 \mathrm{R}$ might be involved in the processing of somatosensory cardinal symptoms and principal components of neuropathic pain, and in the process of cortex plasticity [31]. The authors concluded that, despite the role of microglia in microgliosis, migration, phagocytosis and synaptic pruning process, its direct effects on the pathogenesis and modulation of neuropathic pain are still unclear.

Furthermore, one of the most widely investigated pathways in the spinal inhibitory control of neuropathic pain involves the endogenous neuropeptide Y. However, its role as a pain regulator is far from being completely understood due to the complex expression of its receptors in both post-synaptic neurons and in the central terminals of primary afferents [32]. Moreover, abnormal sensory messages stimulating the cortex areas might induce stimulation in limbic regions that might be implicated in anxiety, depression and sleep problems related to high neuropathic pain ratings [30]. Similarly, the cingulate cortex and amygdala modulate descending controls projections from the periaqueductal grey to the brainstem. At this level, maintenance of the pain state seems to be strictly related to the brainstem excitatory pathways [30].

In this complex framework, a non-painful stimulus of a peripheral nerve could lead to an increase in the neuronal electrical threshold together with a reduction in the conduction 
velocity, resulting in a lower excitability and inhibition of interneurons interrupting the pain signaling [29]. Therefore, targeting specific levels involved in the neuropathic pain circuits might have a role, not only in the pain relief, but also in the complex pathway mentioned above with potential implication in the pain chronicization mechanisms [30].

Indeed, it has been demonstrated that pain relief induced by PENS treatment is mediated by both $A \beta$ fibers modulation and the local release of biochemical mediators such as neurotransmitters and endorphins, hindering the pain response [28].

More in detail, an orthodromic stimulus applied on non-nociceptive $A \beta$ nerve fibers activates respective dorsal horn interneurons and transmits the nociceptive information to peripheral $A \beta$ and $C$ fibers [28]. According to this neurophysiological dynamic, a nonpainful stimulus applied in a peripheral nerve territory can generate a decrease in pain signals [28]. Moreover, non-nociceptive $A \beta$ nerve fibers, after an anterograde activation, might stimulate superficial layer interneurons in the Rexed laminae 2 and 3 of the dorsal horn, which usually process nociceptive signals and transmit the stimulus from $\mathrm{C}$ fibers [33].

How could PENS modulate neuropathic pain? PENS might influence the abnormal electrical discharge typical of chronic pain conditions, decreasing pain perception, a typical feature of neuropathic pain, throughout an electrical stimulation of non-nociceptive fibers [34].

PENS consists of a subcutaneous neuromodulation of nerve structures, through 21 gauge 5 to $20 \mathrm{~cm}$ length modellable needle-electrode monopolar probes, inserted in the skin; then, the probe is tunneled percutaneously through the use of an ultrasound guide along the major axis of the painful area, within the subcutaneous tissue at a depth ranging from 0.5 to $3 \mathrm{~cm}$ [35], as depicted by Figure 1.

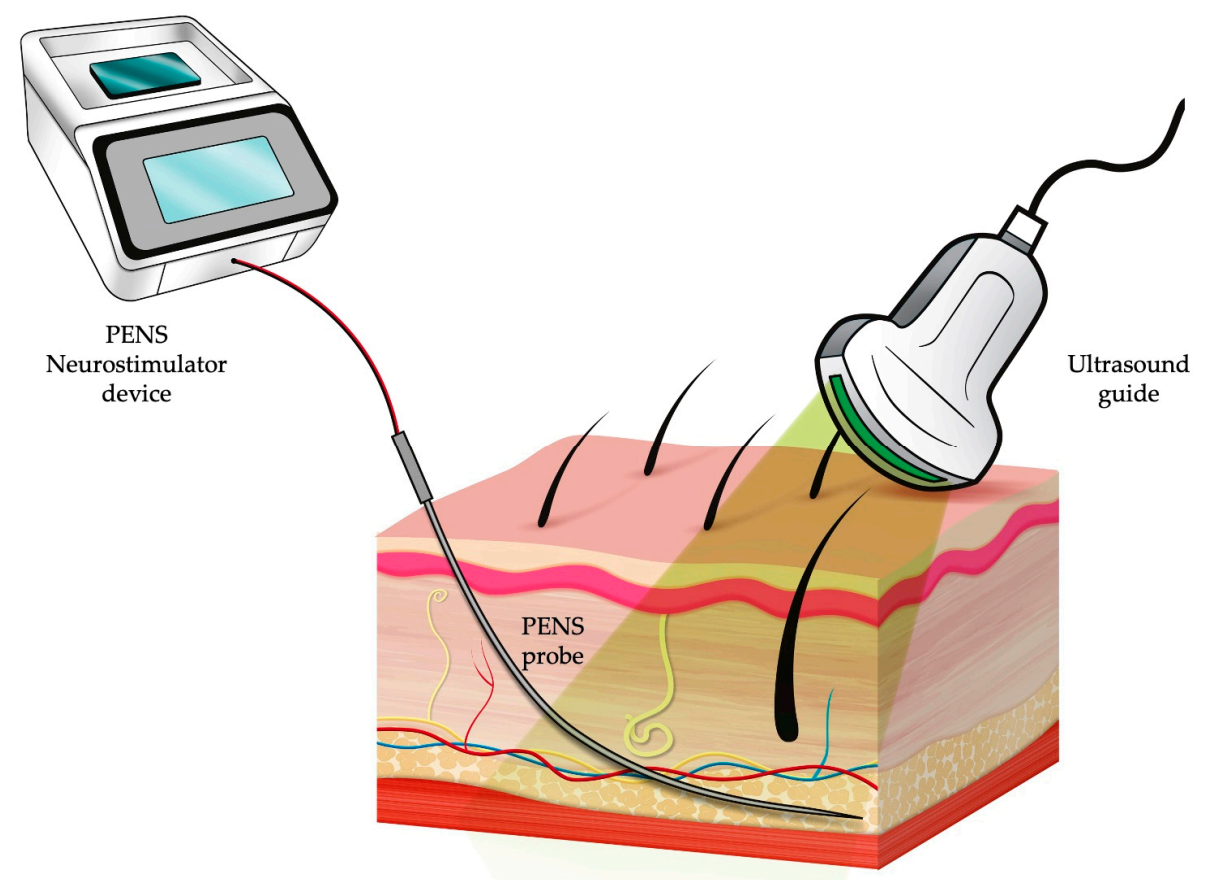

Figure 1. The PENS probe tunneled percutaneously at the subcutaneous level through an ultrasound guide.

The probe is commonly connected to a neurostimulator device with a program of sensitive stimulation at $100 \mathrm{~Hz}$, with an intensity of $0.2 \mathrm{~V}$ until paresthesia along the nerve pathway is obtained. Subsequently, a pulse frequency is commonly applied with an intensity of $0.5 \mathrm{~V}$ and a frequency ranging between $2 \mathrm{~Hz}$ and $100 \mathrm{~Hz}$ every $3 \mathrm{~s}$. The stimulation protocol usually lasts at least $25 \mathrm{~min}$, with continuous supervision by the physician [35]. However, several stimulation programs are reported in the literature, 
characterized by heterogeneous intensity, frequency, duty cycles and treatment duration, according to the different musculoskeletal disorders. The complete PENS treatment set up is depicted in Figure 2.

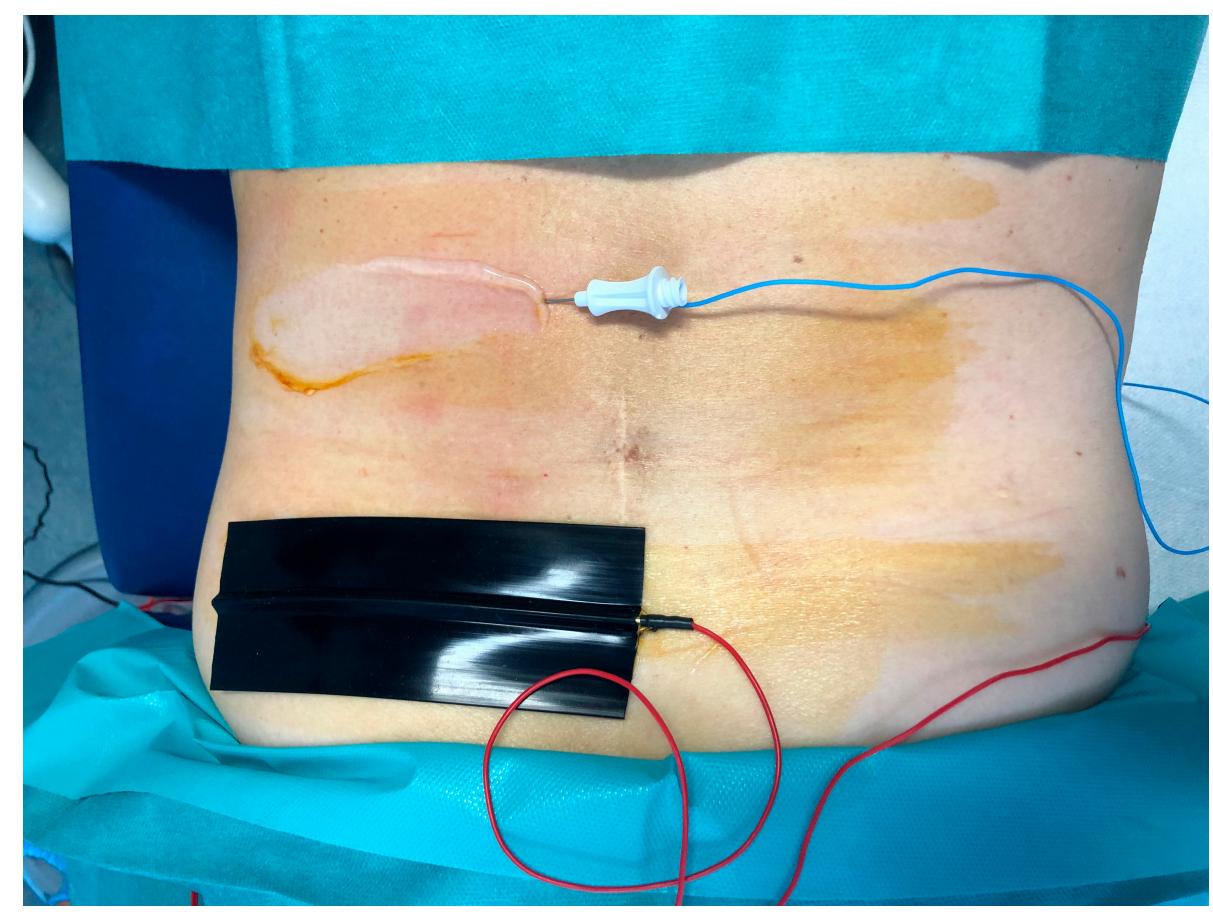

Figure 2. PENS treatment in a patient with low back pain: the needle-electrode monopolar probe is placed at lumbar level.

To date, the PENS technique has been defined as a "rapid emerging field" by the National Institute for Health and Care Excellence (NICE) guidelines [36] and showed to be safe, both in acute and chronic pain management $[7,37,38]$. Chakravarthy et al. showed no complications nor side-effects, such as itching or bleeding from the puncture points after removal of the device, in over 96 patients treated for postoperative pain following cesarean section [39]. To date, the most common adverse event complained by patients in the study of Cohen et al. was a mild discomfort during the probe implantation and/or withdrawal [7].

PENS is not devoid of contraindications that are mainly related to the infective risk, although it is a mini-invasive procedure. In addition, an implanted pacemaker/defibrillator or neurostimulator is considered a common contraindication in the studies currently available in the literature $[5,37,38]$.

Therefore, in light of these considerations, PENS seems to be a safe and well-tolerated therapy in patients suffering from neuropathic and mixed pain. Moreover, it might represent an additional therapeutical option in refractory pain or in patients with relevant comorbidities that contraindicate a conventional approach or pharmacological therapies. In addition, given the low interaction with other therapies, it could be integrated as a complementary treatment with a multimodal rehabilitative intervention, including pharmacological drugs, physical exercise, and instrumental rehabilitative techniques in order to boost the benefits of conventional therapies [5,8,35-37].

However, further studies are warranted to better investigate its tolerability, safety and effectiveness in different pathological painful conditions.

\section{PENS for Low Back Pain}

LBP affects 540 million people worldwide, and it is the most frequent disease suffered by patients referred to the Italian Physical Medicine and Rehabilitation outpatient reha- 
bilitation services [40-42]. Indeed, LBP is one of the main causes of disability worldwide with crucial implications in the rehabilitation field [41]. Thus, the American College of Physicians recommended a multidisciplinary treatment including physical exercise, pharmacological drugs, and interventional rehabilitative approaches for patients suffering from chronic LBP [43].

Among instrumental physical therapies that might be used (e.g., TENS, ultrasound, laser therapy, oxygen-ozone therapy) in the complex multidisciplinary management of LBP [27,44-47], PENS could be mentioned among the innovative approaches to treat this pathological condition, and few promising papers addressed this issue.

A randomized crossover study [5] investigated the effectiveness of PENS therapy, compared with TENS, and physical exercise on pain management in LBP patients. The authors performed a PENS treatment for $30 \mathrm{~min}, 3$ times per week for 3 weeks, on a sample of 50 patients diagnosed with LBP secondary to degenerative disk disease. Their findings showed a significant decrease in Visual Analogue Scale (VAS) pain score in patients treated with PENS compared to those treated with TENS and physical exercise, suggesting that PENS was effective in providing short-term relief and improving physical function in longterm LBP patients [5]. Hsieh and Lee [48] compared the efficacy of a single PENS treatment compared to a single TENS treatment and medication only in 133 patients affected by chronic LBP. They observed that both PENS and TENS induced a significant improvement in VAS pain scale compared to the medication-only group, although no differences between the two intervention groups emerged [48].

Despite these promising results, the long-term efficacy of PENS therapy on LBP is still unclear. In 2004, a study [49] was conducted to evaluate the number of PENS sessions needed to determine analgesic effect and the effect duration in LBP. Patients treated with PENS showed a significant pain and physical impairment reduction, together with decreased NSAIDs use. Thus, they found a significant analgesic effect of cumulative sessions of PENS; however, this benefit gradually faded after discontinuation of treatment [49]. Lastly, a randomized controlled trial [50] conducted with over 200 chronic LBP patients found that all patients treated with PENS showed a reduction in pain and physical impairment, even though general conditioning and aerobic exercise was more effective than PENS alone in reducing fear avoidance beliefs.

Taking into account all these findings, PENS could be considered a valid therapeutic option in patients suffering from chronic LBP, especially in those not responsive to pharmacological interventions, albeit further studies are warranted to support this hypothesis.

\section{PENS for Chronic Knee Pain}

Chronic knee pain is a frequent and disabling condition, commonly related to knee osteoarthritis (KOA). KOA is a musculoskeletal disease characterized by a progressive articular cartilage loss, formation of osteophytes, subchondral bone remodeling and joint inflammation, with a subsequent increased disability and reduced HRQoL [51]. Thus, an early diagnosis of KOA is needed to provide a prompt therapeutic approach [52].

Non-surgical treatments of symptomatic KOA could consist of rehabilitation and pharmacological treatments, such as acetaminophen, NSAIDs and opioids [53]. However, long-term anti-inflammatory treatment is burdened by various side effects, including gastric lesions and a documented progressive decreasing efficacy [54]. Alternatively, intraarticular injections with hyaluronic acid and glucocorticoids appeared to provide pain relief and to recover the viscoelastic properties of the synovial fluid and, thus, might be considered as a second-line approach in patients not responsive to acetaminophen and/or NSAIDs [55].

Furthermore, considering the high prevalence of chronic knee pain (up to $25 \%$ of adults) and the progressive ageing of the population [56], new therapeutic approaches are strongly required to face this emerging medical need. Therefore, in the recent past, there has been an increasing focus in other non-pharmacological treatments of KOA, including focal vibration [57], intra-articular oxygen-ozone $\left(\mathrm{O}_{2} \mathrm{O}_{3}\right)$ therapy [58], radiofrequency (RF) 
ablation of genicular nerves [59], platelet-rich plasma (PRP) injections [60] and PENS [61]. In this context, PENS has been proposed as a novel therapeutic approach for KOA in reducing pain and improve functioning [61]. Indeed, He et al. [61] investigated the use of PENS on 72 patients affected by chronic knee pain, comparing real PENS + etoricoxib with sham PENS + etoricoxib over an 8 week protocol. They found a significant improvement in pain assessed through the Numeric Rating Scale and the Western Ontario and McMaster Universities Arthritis Index in the real PENS + etoricoxib group, suggesting that this multimodal approach could effectively treat chronic knee pain [61].

In conclusion, although little evidence is in the literature, we might hypothesize a potential benefit of PENS treatment on chronic knee pain in terms of pain reduction. However, further studies are warranted to support this hypothesis.

\section{Other Applications and Future Perspectives}

The role of PENS in chronic and refractory pain management has been also investigated in other medical research fields, including oncology, gynecology and neurology.

Indeed, in 1998, Ahmed et al. [8] assessed the effects of PENS in the management of opioid-resistant cancer pain in three cancer patients with bone metastases. More in detail, the authors performed $30 \mathrm{~min}$ of electrical stimulation through acupuncture-like needle probes, at $4-100 \mathrm{~Hz}$ of frequency, in three or more sessions. Their findings were noteworthy, considering that significant pain relief lasted 24-72 $\mathrm{h}$ and was achieved in two of three patients, supporting the hypothesis that PENS might be used as complementary therapy to manage opioid-resistant cancer pain in terminal cancer patients [8]. In 2018, Fu et al. [62] investigated the effectiveness of PENS treatment in reducing fatigue caused by chemotherapy in 83 cervical cancer survivors. The authors found that PENS did not significantly reduce fatigue, suggesting that its role should be limited only to pain management [62].

Another application of this innovative technique could be for headache, as reported by Ahmed et al. [63]. The authors assessed 30 patients with either tension headache, migraine or posttraumatic headache symptoms, lasting for at least 6 months. The sample was randomly divided into two groups: the first performed PENS (needles with electricity) while the second performed a sham treatment ("needles alone"). The protocol consisted of $30 \mathrm{~min}, 3$ times per week for 2 consecutive weeks. Moreover, according to the crossover study design, after 1 week off, the patients underwent the other intervention. The authors showed that PENS was significantly effective in decreasing the overall VAS pain scores for tension-type headache, migraine and posttraumatic headache, suggesting the use of this technique as a complementary therapy to analgesic and antimigraine drugs for the short-term management of headache symptoms.

Taking into account all the possible clinical implications of a wide use of PENS technique among clinicians, we might assume that this treatment strategy could rapidly spread in the medical field as an effective and safe treatment acting on pain reduction.

\section{Conclusions}

In conclusion, this comprehensive review described the state of the- art about potential applications of PENS in chronic mixed and refractory pain, suggesting its potential indication in the multimodal rehabilitative management of chronic musculoskeletal disorders. As previously described, musculoskeletal disorders characterized by mixed chronic pain are a crucial health issue with relevant implications in terms of residual disability and functioning, and HRQoL impairment. These complex pathological conditions need multimodal and comprehensive management characterized by effective therapeutic options, including pharmacological drugs, physical exercise and instrumental rehabilitative techniques. In this scenario, PENS might be considered a promising conservative and mini-invasive intervention to manage mixed pain conditions and pain refractory to other pharmacological interventions. To date, PENS efficacy and safety has been mainly investigated in LBP and knee osteoarthritis only, but it is mandatory to underline that the high heterogeneity of the 
available literature on this topic does not allow to draw any strong conclusion. However, the limited evidence summarized in this review might pave the way to future works on this novel, promising technique, and future randomized controlled trials are warranted to confirm the efficacy of PENS in the complex management of chronic and refractory pain conditions.

Author Contributions: Study design and conceptualization, A.d.S. and M.I.; database searching, A.d.S., L.L. and G.F.; data synthesis and interpretation, A.d.S., A.A. and M.I.; manuscript drafting: A.d.S.; critical revision, M.I.; visualization, A.A., L.L., G.F. and C.C.; study supervision, C.C.; study submission, A.d.S. and M.I. All authors have read and agreed to the published version of the manuscript.

Funding: This research received no external funding.

Institutional Review Board Statement: The study was conducted according to the guidelines of the Declaration of Helsinki and approved by the Institutional Review Board.

Informed Consent Statement: Not applicable.

Data Availability Statement: Not applicable.

Conflicts of Interest: The authors declare no conflict of interest. Funders had no role in the design of the study; in the collection, analyses, or interpretation of data; in the writing of the manuscript, or in the decision to publish the results.

\section{References}

1. Kosek, E.; Cohen, M.; Baron, R.; Gebhart, G.F.; Mico, J.A.; Rice, A.S.; Rief, W.; Sluka, A.K. Do we Need a Third Mechanistic Descriptor for Chronic Pain States? Pain 2016, 157, 1382-1386. [CrossRef]

2. Freynhagen, R.; Parada, H.A.; Calderon-Ospina, C.A.; Chen, J.; Rakhmawati Emril, D.; Fernández-Villacorta, F.J.; Franco, H.; Ho, K.Y.; Lara-Solares, A.; Li, C.C.; et al. Current Understanding of the Mixed Pain Concept: A Brief Narrative Review. Curr. Med. Res. Opin. 2019, 35, 1011-1018. [CrossRef]

3. Gálvez, R.; Marsal, C.; Vidal, J.; Ruiz, M.; Rejas, J. Cross-Sectional Evaluation of Patient Functioning and Health-Related Quality of Life in Patients with Neuropathic Pain Under Standard Care Conditions. Eur. J. Pain 2007, 11, 244-255. [CrossRef]

4. Rauck, R.L.; Cohen, S.P.; Gilmore, C.A.; North, J.M.; Kapural, L.; Zang, R.H.; Grill, J.H.; Boggs, J.W. Treatment of Post-Amputation Pain with Peripheral Nerve Stimulation. Neuromodulation 2014, 17, 188-197. [CrossRef] [PubMed]

5. Gilmore, C.A.; Kapural, L.; McGee, M.J.; Boggs, J.W. Percutaneous Peripheral Nerve Stimulation for Chronic Low Back Pain: Prospective Case Series With 1 Year of Sustained Relief Following Short-Term Implant. Pain Pract. 2020, 20, 310-320. [CrossRef]

6. Ilfeld, B.M.; Gilmore, C.A.; Grant, S.A.; Bolognesi, M.P.; Del Gaizo, D.J.; Wongsarnpigoon, A.; Boggs, J.W. Ultrasound-guided Percutaneous Peripheral Nerve Stimulation for Analgesia following Total Knee Arthroplasty: A Prospective Feasibility Study. J. Orthop. Surg. Res. 2017, 12, 4. [CrossRef] [PubMed]

7. Cohen, S.P.; Gilmore, C.A.; Rauck, R.L.; Lester, D.D.; Trainer, R.J.; Phan, T.; Kapural, L.; North, J.M.; Crosby, N.D.; Boggs, J.W. Percutaneous Peripheral Nerve Stimulation for the Treatment of Chronic Pain Following Amputation. Mil. Med. 2019, 184, 267-274. [CrossRef]

8. Ahmed, H.E.; Craig, W.F.; White, P.F.; Huber, P. Percutaneous Electrical Nerve Stimulation (PENS): A Complementary Therapy for the Management of Pain Secondary to Bony Metastasis. Clin. J. Pain. 1998, 14, 320-323. [CrossRef] [PubMed]

9. Barroso, U., Jr.; de Azevedo, A.R.; Cabral, M.; Veiga, M.L.; Braga, A.A.N.M. Percutaneous Electrical Stimulation for Overactive Bladder in Children: A Pilot Study. J. Pediatr. Urol. 2019, 15, e1-e38. [CrossRef]

10. IASP Announces Revised Definition of Pain-IASP. Available online: https://www.iasp-pain.org/PublicationsNews/ NewsDetail.aspx?ItemNumber=10475 (accessed on 14 November 2020).

11. Woolf, C.J.; Ma, Q. Nociceptors-Noxious Stimulus Detectors. Neuron 2007, 55, 353-364. [CrossRef]

12. Woolf, C.J. What is this Thing Called Pain? J. Clin. Investig. 2010, 120, 3742-3744. [CrossRef]

13. Cavalli, E.; Mammana, S.; Nicoletti, F.; Bramanti, P.; Mazzon, E. The Neuropathic Pain: An Overview of the Current Treatment and Future Therapeutic Approaches. Int. J. Immunopathol. Pharmacol. 2019, 33, 2058738419838383. [CrossRef] [PubMed]

14. Gierthmühlen, J.; Baron, R. Neuropathic Pain. Semin Neurol. 2016, 36, 462-468. [PubMed]

15. Clauw, D.J.; Essex, M.N.; Pitman, V.; Jones, K.D. Reframing Chronic Pain as a disease, not a Symptom: Rationale and Implications for Pain Management. Postgrad. Med. 2019, 131, 185-198. [CrossRef]

16. Taylor, R.S. Epidemiology of Refractory Neuropathic Pain. Pain Pract. 2006, 6, 22-26. [CrossRef]

17. Iolascon, G.; de Sire, A.; Moretti, A.; Gimigliano, F. Complex Regional Pain Syndrome (CRPS) Type I: Historical Perspective and Critical Issues. Clin. Cases Miner. Bone Metab. 2015, 12 (Suppl. 1), 4-10. [CrossRef]

18. de Sire, A.; Paoletta, M.; Moretti, A.; Brandi, M.L.; Iolascon, G. Complex Regional Pain Syndrome: Facts on Causes, Diagnosis and Therapy. Clin. Cases Miner. Bone Metab. 2018, 15, 166-172. 
19. Bernetti, A.; Agostini, F.; de Sire, A.; Mangone, M.; Tognolo, L.; Di Cesare, A.; Ruiu, P.; Paolucci, T.; Invernizzi, M.; Paoloni, M. Neuropathic Pain and Rehabilitation: A Systematic Review of International Guidelines. Diagnostics 2021, 11, 74. [CrossRef]

20. Chaparro, L.E.; Wiffen, P.J.; Moore, R.A.; Gilron, I. Combination Pharmacotherapy for the Treatment of Neuropathic Pain in Adults. Cochrane Database Syst. Rev. 2012, 7, CD008943.

21. Macone, A.; Otis, J.A.D. Neuropathic Pain. Semin Neurol. 2018, 38, 644-653.

22. Meacham, K.; Shepherd, A.; Mohapatra, D.P.; Haroutounian, S. Neuropathic Pain: Central vs. Peripheral Mechanisms. Curr. Pain Headache Rep. 2017, 21, 28. [CrossRef]

23. Romanò, C.L.; Romanò, D.; Lacerenza, M. Antineuropathic and Antinociceptive Drugs Combination in Patients with Chronic Low Back Pain: A Systematic Review. Pain Res. Treat. 2012, 2012, 154781. [CrossRef]

24. French, H.P.; Smart, K.M.; Doyle, F. Prevalence of Neuropathic Pain in Knee or Hip Osteoarthritis: A Systematic Review and Meta-Analysis. Semin. Arthritis Rheum. 2017, 47, 1-8. [CrossRef] [PubMed]

25. St John Smith, E. Advances in Understanding Nociception and Neuropathic Pain. J. Neurol. 2018, 265, 231-238. [CrossRef] [PubMed]

26. Scascighini, L.; Toma, V.; Dober-Spielmann, S.; Sprott, H. Multidisciplinary Treatment for Chronic Pain: A Systematic Review of Interventions and Outcomes. Rheumatology 2008, 47, 670-678. [CrossRef]

27. de Sire, A.; Baricich, A.; Minetto, M.A.; Cisari, C.; Invernizzi, M. Low Back Pain related to a Sacral Insufficiency Fracture: Role of Paravertebral Oxygen-Ozone Therapy in a Paradigmatic Case of Nociplastic Pain. Funct Neurol. 2019, 34, 119-122.

28. Papuć, E.; Rejdak, K. The role of Neurostimulation in the Treatment of Neuropathic Pain. Ann. Agric. Environ. Med. 2013, 1, 14-17.

29. Braz, J.; Solorzano, C.; Wang, X.; Basbaum, A.I. Transmitting Pain and Itch Messages: A Contemporary View of the Spinal Cord Circuits that Generate Gate Control. Neuron 2014, 82, 522-536. [CrossRef] [PubMed]

30. Colloca, L.; Ludman, T.; Bouhassira, D.; Baron, R.; Dickenson, A.H.; Yarnitsky, D.; Freeman, R.; Truini, A.; Attal, N.; Finnerup, N.B.; et al. Neuropathic Pain. Nat. Rev. Dis. Primers 2017, 3, 17002. [CrossRef] [PubMed]

31. Tsuda, M.; Koga, K.; Chen, T.; Zhuo, M. Neuronal and Microglial Mechanisms for Neuropathic Pain in the Spinal Dorsal Horn and Anterior Cingulate Cortex. J. Neurochem. 2017, 141, 486-498. [CrossRef]

32. Nelson, T.S.; Fu, W.; Donahue, R.R.; Corder, G.F.; Hökfelt, T.; Wiley, R.G.; Taylor, B.K. Facilitation of Neuropathic Pain by the NPY Y1 Receptor-Expressing Subpopulation of Excitatory Interneurons in the Dorsal Horn. Sci. Rep. 2019, 9, 7248. [CrossRef] [PubMed]

33. Shaparin, N.; Gritsenko, K.; Garcia-Roves, D.F.; Shah, U.; Schultz, T.; DeLeon-Casasola, O. Peripheral Neuromodulation for the Treatment of Refractory Trigeminal Neuralgia. Pain Res. Manag. 2015, 20, 63-66. [CrossRef] [PubMed]

34. Chakravarthy, K.; Nava, A.; Christo, P.J.; Williams, K. Review of Recent Advances in Peripheral Nerve Stimulation (PNS). Curr. Pain Headache Rep. 2016, 20, 60. [CrossRef] [PubMed]

35. Rossi, M.; DeCarolis, G.; Liberatoscioli, G.; Iemma, D.; Nosella, P.; Nardi, L.F. A Novel Mini-invasive Approach to the Treatment of Neuropathic Pain: The PENS Study. Pain Phys. 2016, 19, E121-E128.

36. Overview I Percutaneous Electrical Nerve Stimulation for Refractory Neuropathic Pain I Guidance I NICE. Available online: https: / / www.nice.org.uk/guidance/ipg450 (accessed on 7 November 2020).

37. Ilfeld, B.M.; Gabriel, R.A.; Said, E.T.; Monahan, A.M.; Sztain, J.F.; Abramson, W.B.; Khatibi, B.; Finneran, J.J.; Jaeger, P.T.; Schwartz, A.K.; et al. Ultrasound-Guided Percutaneous Peripheral Nerve Stimulation: Neuromodulation of the Femoral Nerve for Postoperative Analgesia Following Ambulatory Anterior Cruciate Ligament Reconstruction: A Proof of Concept Study. Neuromodulation 2019, 22, 621-629. [CrossRef]

38. Wilson, R.D.; Gunzler, D.D.; Bennett, M.E.; Chae, J. Peripheral Nerve Stimulation Compared with Usual Care for Pain Relief of Hemiplegic Shoulder Pain: A Randomized Controlled Trial. Am. J. Phys. Med. Rehabil. 2014, 93, 17-28. [CrossRef]

39. Chakravarthy, M.; Prashanth, A.; George, A. Evaluation of Percutaneous Electrical Nerve Stimulation of the Auricle for Relief of Postoperative Pain Following Cesarean Section. Med. Acupunct. 2019, 31, 281-288. [CrossRef]

40. Dionne, C.E.; Dunn, K.M.; Croft, P.R.; Nachemson, A.L.; Buchbinder, R.; Walker, B.F.; Wyatt, M.; Cassidy, J.D.; Rossignol, M.; Leboeuf-Yde, C.; et al. A Consensus Approach Toward the Standardization of Back Pain Definitions for Use in Prevalence Studies. Spine 2008, 33, 95-103. [CrossRef]

41. Hartvigsen, J.; Hancock, M.J.; Kongsted, A.; Louw, Q.; Ferreira, M.L.; Genevay, S.; Hoy, D.; Karppinen, J.; Pransky, G.; Sieper, J.; et al. What Low Back Pain is and Why We Need to Pay Attention. Lancet 2018, 391, 2356-2367. [CrossRef]

42. Gimigliano, F.; De Sire, A.; Gastaldo, M.; Maghini, I.; Paoletta, M.; Pasquini, A.; Boldrini, P.; Selb, M.; Prodinger, B.; Abbamonte, M.; et al. Use of the International Classification of Functioning, Disability and Health Generic-30 Set for the characterization of outpatients: Italian Society of Physical and Rehabilitative Medicine Residents Section Project. Eur. J. Phys. Rehabil. Med. 2019, 55, 258-264. [CrossRef]

43. Qaseem, A.; Wilt, T.J.; McLean, R.M.; Forciea, M.A. Clinical Guidelines Committee of the American College of Physicians. Noninvasive Treatments for Acute, Subacute, and Chronic Low Back Pain: A Clinical Practice Guideline from the American College of Physicians. Ann. Intern. Med. 2017, 166, 514-530. [CrossRef]

44. Urits, I.; Burshtein, A.; Sharma, M.; Testa, L.; Gold, P.A.; Orhurhu, V.; Viswanath, O.; Jones, M.R.; Sidransky, M.A.; Spektor, B.; et al. Low Back Pain, a Comprehensive Review: Pathophysiology, Diagnosis, and Treatment. Curr. Pain Headache Rep. 2019, 23, 23. [CrossRef] [PubMed] 
45. Akhtar, M.W.; Karimi, H.; Gilani, S.A. Effectiveness of Core Stabilization Exercises and Routine Exercise Therapy in Management of Pain in Chronic Non-Specific Low Back Pain: A Randomized Controlled Clinical Trial. Pak. J. Med. Sci. 2017, 33, $1002-1006$. [CrossRef]

46. Wu, L.C.; Weng, P.W.; Chen, C.H.; Huang, Y.Y.; Tsuang, Y.H.; Chiang, C.J. Literature Review and Meta-Analysis of Transcutaneous Electrical Nerve Stimulation in Treating Chronic Back Pain. Reg. Anesth. Pain Med. 2018, 43, 425-433. [CrossRef]

47. de Sire, A.; Agostini, F.; Lippi, L.; Mangone, M.; Marchese, S.; Cisari, C.; Bernetti, A.; Invernizzi, M. Oxygen-Ozone Therapy in the Rehabilitation Field: State of the Art on Mechanisms of Action, Safety and Effectiveness in Patients with Musculoskeletal Disorders. Biomolecules. 2021, 11, 356. [CrossRef] [PubMed]

48. Hsieh, R.L.; Lee, W.C. One-Shot Percutaneous Electrical Nerve Stimulation vs. Transcutaneous Electrical Nerve Stimulation for Low Back Pain: Comparison of Therapeutic Effects. Am. J. Phys. Med. Rehabil. 2002, 81, 838-843. [CrossRef] [PubMed]

49. Yokoyama, M.; Sun, X.; Oku, S.; Taga, N.; Sato, K.; Mizobuchi, S.; Takahashi, T.; Morita, K. Comparison of Percutaneous Electrical Nerve Stimulation with Transcutaneous Electrical Nerve Stimulation for Long-Term Pain Relief in Patients with Chronic Low Back Pain. Anesth. Analg. 2004, 98, 1552-1556. [CrossRef] [PubMed]

50. Weiner, D.K.; Perera, S.; Rudy, T.E.; Glick, R.M.; Shenoy, S.; Delitto, A. Efficacy of Percutaneous Electrical Nerve Stimulation and Therapeutic Exercise for Older Adults with Chronic Low Back Pain: A Randomized Controlled Trial. Pain 2008, 140, 344-357. [CrossRef]

51. McDonough, C.M.; Jette, A.M. The Contribution of Osteoarthritis to Functional Limitations and Disability. Clin. Geriatr. Med. 2010, 26, 387-399. [CrossRef]

52. Iolascon, G.; Gimigliano, F.; Moretti, A.; De Sire, A.; Migliore, A.; Brandi, M.L.; Piscitelli, P. Early Osteoarthritis: How to Define, Diagnose, and Manage. A Systematic Review. Eur. Geriatr. Med. 2017, 8, 383-396. [CrossRef]

53. McAlindon, T.E.; Bannuru, R.; Sullivan, M.C.; Arden, N.K.; Berenbaum, F.; Bierma-Zeinstra, S.M.; Hawker, G.A.; Henrotin, Y.; Hunter, D.J.; Kawaguchi, H.; et al. OARSI Guidelines for the Non-Surgical Management of Knee Osteoarthritis. Osteoarthr. Cartil. 2014, 22, 363-388. [CrossRef]

54. de Sire, A.; de Sire, R.; Petito, V.; Masi, L.; Cisari, C.; Gasbarrini, A.; Scaldaferri, F.; Invernizzi, M. Gut-Joint Axis: The Role of Physical Exercise on Gut Microbiota Modulation in Older People with Osteoarthritis. Nutrients 2020, 12, 574. [CrossRef] [PubMed]

55. Migliore, A.; Paoletta, M.; Moretti, A.; Liguori, S.; Iolascon, G. The Perspectives of Intra-Articular Therapy in the Management of Osteoarthritis. Expert Opin. Drug Deliv. 2020, 17, 1213-1226. [CrossRef]

56. Bunt, C.W.; Jonas, C.E.; Chang, J.G. Knee Pain in Adults and Adolescents: The Initial Evaluation. Am. Fam Phys. 2018, 98, 576-585.

57. Rabini, A.; De Sire, A.; Marzetti, E.; Gimigliano, R.; Ferriero, G.; Piazzini, D.B.; Iolascon, G.; Gimigliano, F. Effects of Focal Muscle Vibration on Physical Functioning in Patients with Knee Osteoarthritis: A Randomized Controlled Trial. Eur. J. Phys. Rehabil. Med. 2015, 51, 513-520. [PubMed]

58. de Sire, A.; Stagno, D.; Minetto, M.A.; Cisari, C.; Baricich, A.; Invernizzi, M. Long-Term Effects of Intra-Articular Oxygen-Ozone Therapy Versus Hyaluronic Acid in Older People Affected by Knee Osteoarthritis: A Randomized Single-Blind Extension Study. J. Back Musculoskelet Rehabil. 2020, 33, 347-354. [CrossRef]

59. Mariconda, C.; Megna, M.; Farì, G.; Bianchi, F.P.; Puntillo, F.; Correggia, C.; Fiore, P. Therapeutic Exercise and Radiofrequency in the Rehabilitation Project for Hip Osteoarthritis Pain. Eur. J. Phys. Rehabil. Med. 2020, 56, 451-458. [PubMed]

60. Gato-Calvo, L.; Magalhaes, J.; Ruiz-Romero, C.; Blanco, F.J.; Burguera, E.F. Platelet-Rich Plasma in Osteoarthritis Treatment: Review of Current Evidence. Ther. Adv. Chronic Dis. 2019, 10, 2040622319825567. [CrossRef] [PubMed]

61. He, D.P.; Zhang, J.; Bai, Z.F. Percutaneous Electrical Nerve Stimulation for Chronic Knee Pain: A Randomized, Sham-controlled Trial. Altern. Ther. Health Med. 2019, 25, 30-34.

62. Fu, T.; Guang, H.J.; Gao, X.Z. Percutaneous Nerve Electrical Stimulation for Fatigue Caused by Chemotherapy for Cervical Cancer. Medicine 2018, 97, e12020.

63. Ahmed, H.E.; White, P.F.; Craig, W.F.; Hamza, M.A.; Ghoname, E.S.; Gajraj, N.M. Use of Percutaneous Electrical Nerve Stimulation (PENS) in the Short-Term Management of Headache. Headache 2000, 40, 311-315. [CrossRef] 